\title{
De fonética y léxico del español común en versión sefardita de 1720
}

\author{
Juan Antonio Frago ${ }^{1}$ \\ Universidad de Zaragoza, España
}

\begin{abstract}
Resumen
Se estudian aquí cuestiones que tienen que ver con la historia del español atestiguadas en traducción de los salmos de David de un rabino jamaicano, cumplida a finales del siglo XVII y con publicación londinense en colaboración de un grupo de influyentes y muy cultos sefarditas. La versificación del corpus permite establecer con toda seguridad el valor cultural de la forma fee, y de elementos grafémicamente semejantes (vee, see), en relación con la moda escrituraria y el peso de la tradición forense. La rima en versos esdrújulos da asimismo firmeza diacrónica a varios proparoxítonos ultracorrectos que en la obra de Daniel Israel se hallan, de problemática concerniente tanto al español europeo como al americano, y el análisis apunta también a la necesidad de que en el diccionario académico se revisen etimológicamente las entradas vaguido, con su inclusión de váguido, y vahído, en conjunción de documentación y evolución fonética.
\end{abstract}

Palabras clave: texto sefardí e historia del español, fee en la lengua escrita, esdrújulos ultracorrectos, documentación y etimología.

1 Para correspondencia, dirigirse a: Juan Antonio Frago (jafrago@unizar.es), Universidad de Zaragoza, Paseo de las Damas, 44, $2^{\circ}$ izda, 50008 Zaragoza, España. 
Of phonetics and lexicon from General Spanish in Sephardic VERSION OF 1720

\begin{abstract}
The present paper studies issues related to the history of Spanish attested in a translation of David's psalms by a Jamaican rabbi, completed in the late 17 th century and with a London publication in collaboration with a group of influential and highly cultured Sephardim. The versification of the corpus makes it possible to establish with complete certainty the cultural value of the fee form, and of graphically similar elements (vee, see), in relation to the fashion of writing and the weight of the forensic tradition. The rhyme in proparoxytone verses also gives diachronic firmness to several hypercorrect proparoxytones found in Daniel Israel's work, of problems concerning both European and American Spanish, and the analysis also points to the need for revision of the etymologies of the entries vaguido, with its inclusion of váguido, and vahído in the Academy's dictionary, in conjunction with documentation and phonetic evolution.
\end{abstract}

Keywords: Sephardic text and history of Spanish, fee in written language, hypercorrect proparoxytones, documentation and etymology.

Recibido: 11/01/20 Aceptado: 09/03/20

\title{
1. ADVERTENCIA PREVIA
}

El corpus aquí considerado ofrece una urdimbre que mira al castellano medieval y también a la posterior evolución tanto de la lengua común, o castellano "universal" según lo llamó el maestro Correas, como al complejo dialectal judeoespañol, con la inevitable, por normal, adherencia de específicos rasgos debidos a la traducción del hebreo al romance. Importa mucho conocer las raíces hispánicas de la diáspora en materia de idioma y el hecho de que su contacto con el español posterior a la expulsión no se interrumpiera tajantemente para todos los exiliados en el conjunto de las comunidades sefarditas, particularmente en los grupos más pudientes y cultos, estos asimismo familiarizados con el español escrito, sin contar con las salidas de conversos españoles y portugueses hasta bien entrado el siglo XVIII, huyendo de la represión inquisitorial y para poder practicar abiertamente la religión de sus mayores. 
La perspectiva del historiador del judeoespañol necesariamente ha de ser de muy amplia diacronía, empezando por el periodo medieval, en el que ya antes de 1492 el bilingüismo del hebreo con el romance, predominantemente castellano en el cuatrocientos, pero también el catalán, aragonés y gallego de no pocos miembros de las juderías peninsulares, condicionó su expresión románica, junto a otros factores, el principal quizá el apego a la tradición de estas comunidades. Algunos estudiosos minimizan al máximo el mantenimiento de la lengua sagrada por los judíos españoles cuando se acercaba su expulsión, pero no debían de ser pocos los que lo dominaban cuando en ordinación oscense de 1416 se prohibía su empleo en los tratos comerciales:

Item, ordenamos que corredor alguno fendo o tractando mercado alguno no favle en ebrayco ni en alfaravía i en bescunz ni en otro lenguatge escuro, sino su lenguatge, en manera que entramas las partes lo intendan, en pena de trenta sueldos. (Falcón Pérez 1991: 252)

A esa pervivencia lingüística alude la conversación a escondidas entre dos cristianos nuevos del círculo de Fernando el Católico, temerosos de ser señalados como partícipes en la conspiración contra el inquisidor Pedro de Arbués, y que en 1485 encargaron al rabino de la judería rural de Magallón les escribiera conjuros a las estrellas en hebreo; el que don Salomón Atortox, mercader de dicha aljama "en judayquo fiço fe" en un inventario notarial del 2 de mayo de 1492, también que los cristianos dijeran que los judíos entre sí hablaban "con la gorja" y que entre confesas de Calatayud corriera el dicho "judíos me da fijos, yo les faré aprender ebrayco".

Significativos son además los testimonios de seseo, de formas como corneya 'corneja', meyesa, femenino de mege 'médico', dichas en procesos inquisitoriales de Aragón, también de avanti 'avante' y ponti 'ponte', y de cierres de $-o$ en $-u$ puestos en boca de judíos, judaizantes y conversos recientes (amatu, caldeu, duelu, royu, etc.), así como el que los mozos de Daroca vestidos de judíos cantaran "De las coles, con el culantru, oréganu", fenómenos estos que por cierto se dan en los Proverbios morales de SemTob, equivocadamente considerados occidentalismos por sus estudiosos. De manera que un cierto judeoespañol sí existió antes de la expulsión, a lo que también apunta la coincidencia en mantener rasgos entonces en decadencia, del tipo la mi madre, nos y vos para sujeto, del vos átono (vos digo), de los etimológicos do, estó, so, vo, cuando ya primaba entre cultos la innovación con $-y$, o de cabdal, cibdad a la sazón en competencia diatópica y sociocultural con caudal, ciudad, con tantas otras facetas definitorias que la historia del castellano medieval es capaz de ajustar a la de las hablas sefarditas. (Frago 2019) 


\section{CORPUS Y AUTOR}

2.1. La obra a la que las siguientes notas lingüísticas pertenecen se publicó en Londres (López Laguna 1720), pero su composición se había iniciado en Jamaica hacia 1696, habiendo trabajado en ella su autor veintitrés años, a tenor de lo que se afirma en uno de los textos prologales que la adornan. Se trata de una traducción parafrástica de los 150 salmos de David, en gran número de composiciones estróficas de la poesía castellana: canción, canción real, coplas, cuarteta, cuarteto, décima, décima de pie quebrado, endecha, lira, madrigal, octava, redondilla, romance, soneto y terceto, concluyente prueba del extrordinario nivel cultural del traductor y poeta sefardita, que en la Petición a su mecenas refiere:

Quandoumilde su afecto lo suplica

desde Kingstown (Real Pueblo) en Jamaica, de tan grande Portal merced alguna espera con raçón Daniel Laguna ${ }^{2}$

En efecto, este personaje llevaría su manuscrito redactado en la isla antillana a Londres, de donde regresaría con varios ejemplares impresos, uno de los cuales hacia 1780 llegó a manos del ilustrado Comisionado regio Francisco de Saavedra, quien en su Diario relata esta peripecia bibliográfica, consecuencia de su apresamiento por los ingleses cuando navegaba entre Cumaná y Cuba, siendo con mucha consideración tratado por el Gobernador británico y habiendo disfrutado del trato con la elite social y con miembros de la comunidad sefardita en su breve detención jamaicana (Morales Padrón 2004: 77):

Iba algunas veces a vernos un judío cuyo nombre era Aaron Enríquez, anciano de buen carácter y singularmente experto en el comercio de

2 Cito por Espejo fiel esta traducción salmística, en cuya edición existe tildado fonético, pero no en todo coincidente con el de Autoridades, que regularizo en mis menciones, así como su puntuación ortográfica, respetando los demás usos grafémicos del original, menos en los casos de las mayúsculas y de la $v$ vocálica. Los salmos traducidos se refieren con $S$. y Ss. si de uno o de varios se trata, con su correspondiente número. Los textos preliminares en alabanza del autor y de su obra, o con cualquier precisión editorial, se citan por los propios títulos y nombres de sus autores. Hay descripción de esta edición londinense, con algunos datos biográficos del autor, como que era nacido en Portugal (Cabezas Alguacil 1988-1989), mientras Kayserling se refiere a él como "Spanish poet", y desde luego en su lengua todo refiere a un origen hispánico. 
América. De él adquirí varias noticias útiles que se hallan en este diario. Nos enseñó la sinagoga, que es edificio poco notable por su estructura. Nos llevó a casa de un compañero suyo muy rico llamado Jacobo Bernal, que nos dio un espléndido convite a que asistieron muchos oficiales y otras personas distinguidas del país. Enríquez apreciaba mucho los libros españoles y yo le di varios que llevaba. Él me regaló una traducción de los salmos en verso español, hecha en el siglo pasado por un Rabino de Jamaica e impresa en Londres. No hallé cosa alguna en ella opuesta a nuestra religión, pero sí mucho que admirar en la gran variedad de metros que usa el autor, y en la destreza con que maneja el idioma castellano. Dudo que de este libro haya ejemplar alguno en España. Yo se lo regalé por medio de don Ignacio de Hermosilla a la Real Academia de la Lengua ${ }^{3}$.

En 1782 regresó Saavedra a España, donde ya se hallaba en el mes de julio, y en 1789 fallecería Ignacio de Hermosilla, desde 1767 miembro de la Real Academia Española, de modo que entre esos años se entregaría tan preciado libro a esta institución, en cuyos anaqueles se ha guardado sin haber merecido atención lingüística hasta ahora. El completo expurgo de este venerable corpus permitirá el establecimiento de sus peculiaridades sefarditas y su contraste con el español común de la época, con las consecuentes precisiones diacrónicas, tarea que me compromete a un próximo estudio. Ofrezco ahora una primicia filológica del Espejo fiel sobre dos cuestiones de interés para el hispanista testimoniadas en sus páginas.

2.2. En cuanto al autor, el rabino David Israel López Laguna, él mismo proporciona retazos autobiográficos en estas dos primeras décimas de su $A$ el zeloso lector:

\author{
A las musas ynclinado \\ e sido desde mi ynfansia \\ la adolecensia en la Francya \\ zagrada escuela me ha dado,
}

\footnotetext{
3 En la colonia británica estuvo preso Saavedra desde el 10 de noviembre de 1780 al 2 de enero de 1781, y en tan poco tiempo anotó interesantes aspectos de su geografía, organización militar, economía y sociedad, así como de la particularidad de que de los judíos "hay un gran número de ellos" y "son los factores del contrabando con los españoles, para lo que les da mucha proporción el conocimiento de su lengua", es decir que eran sefarditas (ibid., 18, 78, 114).
} 


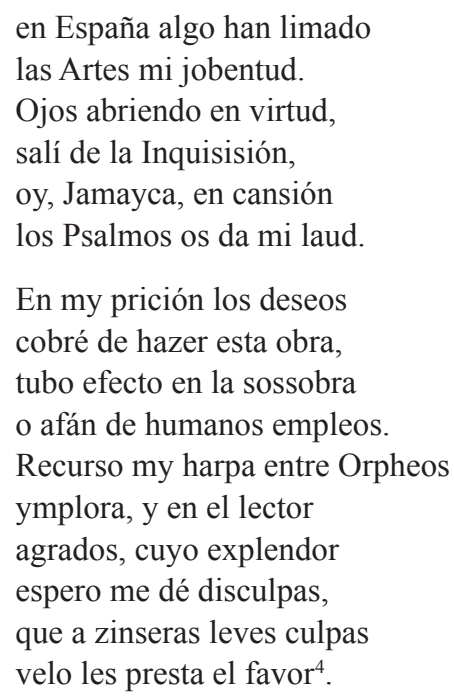

Las primeras 42 páginas anteriores a la traducción de los salmos constituyen una magnífica demostración de hermandad hispano-portuguesa en la diáspora y de refinamiento cultural, con numerosas aportaciones literarias en alabanza del autor y de su obra, incluidos un soneto y una décima de "un anónimo consanguíneo suyo" en buen castellano, además de los textos de sus tres hijos (David, Jacob e Isaac), el primero con alusión a su progenitora Riki, "primer fruto masculino / con que ilustró el Rey divino / a my madre, Rikavid", aparte de las composiciones debidas a la pluma del propio Daniel Israel López Laguna. Hay también en esta parte inicial un epigrama latino del Physicus medicus David Chaves, incluso poesías en inglés, de Samson Guideon junior, de Abraham Bravo y de "an unknown Hand". Aunque se encuentra un autor en portugués, el Dr. Y. de Sequeira Samuda con un soneto y Outavas do mesmo, todo lo demás es castellano, en línea con la letra y el espíritu de la "Aprobación del Excelentíssimo Sr. H.H.R. David Nieto, Rab del K.K. [Kahal Kados] de Londres", que juzgaba necesaria la

$4 \quad$ El autor refiere su inmediata procedencia francesa, con origen en judíos desterrados o huidos, su educación en la ley judaica, posterior paso a la Península para estudiar Artes (lógica, física y metafísica) y humanidades, pues su formación gramatical y literaria es evidente, refiriendo también su prisión en cárcel inquisitorial, donde ideó el que sería su Espejo fiel. Huido del Santo Oficio, quizá mediante soborno, acabaría asentándose en Jamaica, donde fue el judío más sobresaliente y respetado de su tiempo, según Kayserling (1900: 712-713), pero este estudioso leyó Yamayca y yoventud donde pone Jamayca y jobentud. 
impresión del Espejo fiel "para los devotos de nuestra Nación espanola (sic) y portuguesa", pues, como expresa el Prefacio de Jahacob Henríquez Pimentel, aún se exiliaban de España y Portugal y les "es forsoso que lean en lengua castellana, por no entender el sagrado ydioma hebreo". Y digno de mención es el hecho de que en ese ambiente sefardita no faltaran composiciones de mujeres, concretamente una décima "de Doña Sarab de Fonseca Pina y Pimentel al autor" y cuatro décimas "de Dona Manuela Nunes de Almeida, madre del mezenas deste libro, al autor", y otra "de Doña Bienbenida Cohen Belmonte, hermana del mezenas, al autor", todo en lengua española, a pesar de la indudable ascendencia lusa de la apellidada Nunes de Almeida.

Asimismo ofrecen contribuciones en prosa castellana estos prolegómenos, así el Prefacio al lector, de particular interés lingüístico, y la Aprobación, $o$ sea cenzura de Jahacob Henríquez Pimentel "alias don Manuel de Umanes", igualmente autor de varios sonetos, y el retórico texto de la Aprobación de David Nieto, al que sigue una página en hebreo, famoso personaje cuya preeminencia en la judería londinense explícita queda en el tratamiento que se le otorga, quien además de la lengua sagrada de los judíos escribió en español, portugués e italiano, nacido que fue en Venecia el año 1654, muerto en Londres el 1728, antes médico de gran éxito en Livorno, para luego hallarse en la cúpula judaica de Londres (Caro Baroja 1978: II, 477478). Y de ese escogido grupo de sefarditas todo fueron encomios para el Espejo fiel y su autor, en cuyo acervo cultural ni siquiera las referencias mitológicas faltan, con sus Orpheos de la última décima citada, Faetontes (Ss. 18 y 50) y Polifemo (S. 18), y menciones de fénix, sátiros y tántalos (Ss. 23, 81, 82).

\section{LENGUA HABLADA Y ESCRITA: ENTRE EL HIATO Y LA SINÉRESIS}

3.1. En la inicial Dedicatoria en jeroglifico una décima incluye el verso "en quien lo heroico se vee" y en dos cuartetas de la Petición se lee: "bien se vee que es grande Puerta" y "Sahar se vee, pues lo monta", como en glosa final del $S .150$ una décima trae "que no vee quien no te llama" y la siguiente "al ver que en su empleo crese". Todos estos octosílabos lo son el último por su monosílabo ver y los demás por igual razón en su vee con hiato aparente, pues, a tenor de lo que sigue, no es la sinéresis de una licencia poética, sino una fusión vocálica mucho antes fijada, siendo que la 
primera décima de dicha Dedicatoria en jeroglifico, abunda en lo mismo respecto de la forma fee:

\author{
Sin que afán al mundo dé, \\ espejo fiel aquí busca, \\ corona del-fin que lusca \\ con paz, esperanza y fee. \\ En este portal seré \\ fiel gira-sol de fortuna, \\ hasta que vea coluna \\ de mano real generosa \\ a la de este espejo, luna.
}

De nuevo, en posterior pasaje el $S$. 118 ofrece también monosilábica la voz fee, solo grafémicamente bisílaba en el endecasílabo "senda de fee escogí, libre de vicios", incluso con sinalefa entre fee y escogi. Porque esta palabra con letra vocal repetida no solo se halla en la expresión formularia Fee de erratas, corriente en ediciones del siglo XVI y hasta muy avanzado el XVIII, sino en textos poéticos en los que no ayuda a la métrica con el falso añadido de una sílaba: en el verso "con paz, esperança y fee" de la décima arriba citada, y en el del $S$. 142 "quien en su fee la sublima", así como en los romances octosilábicos del $S .78$ "podemos dar fee segura" y $S .143$ "quien en ty mi fee se aviva", así como en la parte en endecasílabos del mismo $S$. 78 "fundado en caridad, fee y esperança".

En cuanto a formas verbales con secuencia grafémica $e$ - $e$, además de los casos que arriba constan deben contarse uno en soneto de Mordejay Nunes Almeida, mecenas de López Laguna, "vee el devoto misterios superiores", asimismo con sinalefa vee el, y "no veen que aunque viviesen" heptasílabo de canción del $S$. 49. Siguiendo el expurgo, "que el refugio se desvía / del hombre al veer su despeño" en décima del $S$. 142, y "al veer su Real Redemptor" con sinéresis abrupta de Real en romance octosilábico del $S$. 149; luego en los endecasílabos "al veerme, qual mis padres, moradiso" en octava del S. 39, y "de amigos vee desvíos que tolera" del Resumen del S. 38.

3.2. Todos los casos de fee de Espejo fiel son monosílabos, el cómputo silábico de sus versos y la rima indiscutiblemente lo demuestran, igual que las formas del verbo ver con secuencia $e-e, \mathrm{y}$ refuerzan este aserto alternancias como "todo lo vee y especula" - "que todo lo ve y escucha", octosílabos de romance en $S$. 78, y la de veer con ver de anteriores ejemplos, a todo lo cual se añade un see, también de una sílaba, en "bien see que estoy sujeto / al tropieso y caída", de versos heptasílabos de canción del S. 38. 
Ciertamente tales testimonios no son exclusivos de este corpus, pues los mismos see y veer monosílabos están en sendas octavas mexicanas de 1755 , "ya see que tú no resives", "del Concejo, que se guardan / donde nadie pueda veerlas", y otro see testimonia un diálogo satírico novohispano de 1785, "cuidado, Tejocote, le dije, que yo see que aquí hai un tal Azeyte Rosado que cojea los que piden", sin que en él falte algún caso de $f e e^{6}$, como otro veer monosilábico de dézima burlesca contra el virrey interino Martín de Mayorga, de hacia 1780: "se quejan malos y buenos / de veer que el pan a ido a menos" 1626 sus escribanos de oficio alternan Santa Fee y Santa Fe, con bastantes casos de fee: "buenafee", "bivir en la fee y creencia", "contra la fee", "sobre cosas tocantes a la fee", etc. ${ }^{8}$

Sin paliativos debe rechazarse el craso error, con otros no menos gruesos, de que se pretenda que "el nombre fee duplica la vocal" (Carrera de la Red 2008: 739-740), tratándose de un diáfano proceso evolutivo: lat. fidem $>$ fee, cuya secuencia vocálica bien se fusionó en $f e$, de temprana documentación, bien por relajamiento del segundo elemento fónico resultó fey, ambas evoluciones normales en castellano (lee $>$ ley, temedes>temees $>$ temés-teméis). Corominas apunta que fey pudo darse "con carácter ocasional", y documenta en el Fuero Juzgo, añadiendo que fee se halla aún "en el S. XVI" (19801991: II, 877). Que de un étimo quedaran en castellano tres formas, fee, $f e$, con la variante aspirada he, y fey durante un segmento diacrónico por ahora indeterminado no es extraño, sí lo sería que fee se hubiera mantenido oralmente vivo hasta finales del siglo XVIII, y lo propio cabe decir de veer y vee. Al término del $\mathrm{XV}$ pervivirían $f e$ y fey, fee acaso en el medio jurídiconotarial, y ni esto es seguro dada la acusada tendencia antihiática de nuestra lengua. Porque aunque de $f e y$ son mínimas las referencias bibliográficas, su mera mención como voz antigua está en García de Diego (1985: 679), es la palabra viva que muchos judíos españoles se llevaron al destierro (Nehama 1977: 209)9.

BNE, El Duende de México. Papeles satíricos en verso, Ms. 21.424-7, fs. 7v, 10v.

6 BNE, Segunda parte de los soñados regocijos de Puebla. Diálogo entre Don Francisco Poderoso y Alcatraz y un mexicano llamado Tejocote, Ms. 13.509, fs. 3r, 32v.

7 BNE, Décima que le han hecho a Don Martín de Mayorga, virrey interino, Ms. 13.244, f. 135. Evidente es que el apodo Aceite Rosado se refiere a la homosexualidad de quien lo lleva y coger al acto sexual.

8 Archivo Histórico Nacional, Inquisición, Proceso contra Francisco de Vitoria Baraona, 1642-2, núm. 9, fs. 6r, 6v, 7r, 7v, 11v, 12v, 20r, 21v, 22r.

9 En el CORDE de sus ocho ejemplos de la forma fey que reúne solo dos corresponden a la voz aquí considerada, "en bona fey", de 1277 y 1315. 
3.3. En el Quijote, no obstante sus numerosos pasajes de rasgos arcaicos en las proclamas del caballero andante, $f e$ predomina con mucho sobre $f e e$, incluso en las locuciones estereotipadas ( a fee, a buena fee / a fe, en $f e$, mía fe, etc.), con bastante clara distinción estilística, sin contar con que diccionarios como los de Nebrija y el de Covarrubias ignoran fee, que en el lenguaje forense tanto tiempo se mantendría, pero no como bisílabo, sobre todo en sus partes más formularias. El empleo de esta forma y de veer, vee en la época de Espejo fiel no fue por realismo lingüístico, mucho menos el de see, sin posibilidad etimológica de haber sido bisílabo, sino porque ese aspecto gráfico de secuencia $e$-e tal vez se consideraría más selecto para la lengua escrita, en el caso de fee con apoyo del prestigio del formalismo jurídico-notarial.

En los escritos oficiales ciertos usos tradicionales fueron de duradero arraigo y ocasionalmente pudieron influir en textos no marcados; así, en otras partes he señalado el empleo de las secuencias $a$ el, de el en el siglo XVIII, el ejemplo " $A$ el zeloso lector" de López Laguna más arriba está (cfr. 2.2.), y a el cuando las correspondientes contracciones llevaban siglos de existencia, igualmente la continuidad de la construcción mío signo al término del documentos notarial hasta entrado el XVII, o el mi regidor en documento de 1801 de la Real Chancillería de Valladolid. Respecto de la cuestión grafémica, Nebrija asume como propio el cambio de cibdad a ciudad, aunque reconociendo que la costumbre escrituraria aún determinaba que a veces se escribiera con $-b$ por quienes seguían la innovación fonética (1517/1977: 113, 138, 148). Y el yeísmo con la connotación cultural que conllevaba en cuanto a vacilaciones ortográficas, condenadas por algunos yeístas, así Fernández de Lizardi en su Periquillo Sarniento, explica que en México se contrapusiera en composición de 1807 el habla del clérigo a la del indio Juan mediante contrastes como el de llevar del culto al yebar del inculto, siendo que ambos practicaban dicha confusión fónica (Frago 2012: 75-77).

\section{ESDRÚJULOS ETIMOLÓGICOS Y ULTRACORRECTOS}

\subsection{DocumentACiÓN}

En Espejo fiel el cultismo léxico se da profusamente, con términos como abstener, arrogante, frivoloso, obstentar, óvalo, proceloso, sumptuoso, terso y tantos más, aunque la marca cultista del autor, que de alguna manera tal vez 
explique su preferencia por fee y vee, particularmente resalta en su generoso recurso al esdrújulo, del que se sirve en sus 23 composiciones en cuartetas de rima esdrújula, modelo poético que en América tuvo seguidores como el culto hatero dominicano José Peguero en sus octavillas burlescas (Vicioso 1979: 304). Y de las composiciones en esta clase de versos consideraremos las voces méndigo, périto, síncero y váguido, las tres primeras de étimos llanos, la cuarta esdrújula en su origen:

De méndigo:

No dejes que buelva el méndigo avergonçado en sus tráphagos;

el pobre, el solo y el mísero tu nombre alaben con cánticos $(S .74)$

De périto:

De sincero:

Yo dixe seréis como ángeles, hijos de Dios, si escolásticos fuereis en el juizio péritos, siguiendo al sabio eclesiástico (S. 82)

Porque es Rey de todo el óbalo terreno, el Dios a quien páxaros dirigen canciones sínzeras, psalmeadle todos los prácticos (S. 47)

Al Dios que afirma los sinzeros justos deseos de mi ánima (S. 57)

De tu compaña lo sínzero no para siempre entre escándalos (S. 74)

Jusgad al mendigo y huérfano al pobre, mísero y lánguido justificad al que, sinzero, carece de auxilio y báculo (S. 82)

Dad al Señor, almas cínseras, honrra de su nombre válido (S. 96)

De váguido:

Pero el gran Dios, alto y único, cortando el buelo a estos páxaros, les dará en flechas de súbito heridas de mortal báguido (S. 64) 


\section{Piadoso gran Dios, apiádame \\ porque en tu abrigo magnánimo \\ logre su amparo mi ánima \\ en días de asombro y báguidos ( $S .57)$}

El carácter esdrújulo de estas formas en rima, sea circunstancial o por condición etimológica, no ofrece duda, lo que no puede decirse del mendigo de la cuarteta del $S .82$ arriba citada, en interior de verso; tampoco sincero en "cinsero y fiel te requiero" y "que a zinseras leves culpas" de décimas del Prólogo del autor, pues nada hay en estos casos, ni en el endecasílabo "sincero, exempto y libre de malicia" de octava del $S$. 17, que permita suponer mutación acentual alguna desde la raíz latina de estas voces.

\subsection{LA CUESTIÓN FILOLÓGICA}

La documentación poética de mendigo, perito y sincero por la rima certifica el cambio de acento llano a esdrújulo, documentación que con anterioridad no se ha registrado, siendo que la seguridad lingüística al respecto solo podrá darse en verso hasta la existencia de una acentuación ortográfica suficientemente regularizada. En el caso de váguido el Autoridades lo ofrece con el tildado regular de los esdrújulos, y váido en diptongo igual que váina, con la advertencia "úsase esta voz más frecuentemente". De modo que los primeros académicos estaban asegurando la pronunciación esdrújula de váguido, desde la que se daría el paso a váido, para ellos ya más usual por entonces, cuya pérdida de la /-g-/ es muy factible, muchísimo menos en la secuencia de estas formas del $D L E$, donde a váguido se da el étimo vaguear, y como voz principal vaguído, de la cual se pasa a vahído con relajamiento consonántico en sílaba tónica de muy difícil justificación ${ }^{10}$.

Para Corominas, "una acentuación vaguído no parece haber existido nunca, aunque la admita la Academia", y el etimólogo propone el origen de

10 En la edición 1992 del DRAE, váguido era primera entrada de esta secuencia léxica, tal vez porque aún se tenían en cuenta los datos del Autoridades, pero condicionado también el lexicógrafo por precedencias en el diccionario académico de una total inconcreción etimológica y de la nota "poco usado" de vaguido, acentuación llana que Corominas cree no "haber existido nunca". Evidentemente no se ha calibrado la correspondiente realidad fonético-fonológica: en el esdrújulo váguido/gi/se halla en la mayor distensión silábica, lo que facilita la pérdida de la velar, mientras que en un paroxítono vaguído al segmento silábico central de la palabra le corresponde la mayor tensión articulatoria, lo que desde luego no facilitaría el relajamiento extremo de dicha consonante. 
váguido en vago 'vacío', con sufijación átona, vágado en portugués, usual hasta el siglo XVIII, que anteriormente daría la variante váido "sin alterar la acentuación inicial", registrada en letrilla octosilábica, "dejó váidos de cabeza, / que amor tray grand pesadumbre", citada por Quevedo y otros, que se consideraría vulgar cuando "la gente educada dio en pronunciar vaído", de aceptación académica en 1780, con $h$ en 1803 (1980-1991: V, 730-731). Otras menciones textuales de váguido, como la de Alonso Fernández de Palencia (1490), o las tres del Quijote (I, 38; II, 37, 41), aunque no lleven tilde y no estén en verso, a tenor de lo que su etimología y documentación indican con toda probabilidad se refieren a la forma esdrújula.

\section{CODA}

En Espejo fiel es constante el significado 'puro' de sincero, atestiguado como esdrújulo en Iriarte y Castelar por Alonso, quien explica un considerable número de voces con traslación acentual, de uso diversamente frecuente, por diferencias de intensidad entre sílabas acentuadas y no acentuadas, por esquemas rítmicos e influjo del acento del singular sobre el del plural, carácter en carácteres, con el factor sociocultural que subyace a su observación de que "Chile tiene un problema especial con sus acentuaciones esdrújulas en palabras completamente populares" (1930: 360, 366, 369). En Aragón es inverso el proceso, pues sus hablas populares manifiestan una acusada tendencia a la conversión de esdrújulos en llanos (apostóles, esparrágos, musíca, pajáros), a la que de vez en cuando se contrapone la reacción del esdrújulo ultracorrecto (carámelos, depórtivo, pántano), llegándose a la pérdida de la vocal postónica en una voz como vispra 'víspera' y comúnmente en las sufijaciones con-ísimo, proceso semejante al que se dio en la evolución de los esdrújulos latinos al romance (carismo 'carísimo', guapismo 'guapísimo', majismo 'majísimo'), que documento en cartas de Goya con las formas bellismo 'bellísimo' y muchisma 'muchísima' (1996: 42), de lo que hay algunas muestras en otras zonas peninsulares, así como en el español de Colombia y de Chile. Es antigua, en efecto, la renuente actitud de sectores populares hacia el arquetípico cultismo del esdrújulo, cuyo abusivo empleo también ha chocado en niveles letrados, en América igualmente, de lo que en el Quijote Cervantes dibuja cuadro sociolingüístico de gran comicidad, cuando la dueña Dolorida enhebra cinco superlativos en-ísimo antes de preguntar por "el acendradísimo caballero don Quijote de la Manchísima y su escuderísimo Panza", replicando este: "El Panza... aquí 
está, y el don Quijotísimo asimismo; y así podréis, dolorosísima dueñisima, decir lo que quisieridísimis, que todos estamos prontos y aparejadísimos a ser vuestros servidorísimos" (II, 38). Al menos curioso es que un largo siglo después, en 1734, la edición de Espejo fiel es de 1720, el autor del Baratillo mexicano jugara de similar manera con el mismo sufijo, al parecer por entonces aún no del todo popular: "Y la cartilla de los epítetos, de profundíssimo, sapientíssimo y demás superlativíssimos que ha de dar y recebir de sus compañeros los graduados con los mismos requisitíssimos" (Frago 2017: 242-243).

Como no parece probable que en Jamaica modelara su español López Laguna, su conocimiento de méndigo debería referirse al trato idiomático en las comunidades sefarditas del mediodía francés o a su estadía en España como escolar de Artes, y posible es que manejara la variación mendigoméndigo con fines métricos y estilísticos. También las ultracorrecciones périto y síncero de sus versos caben en la misma explicación, referente a una sincronía de abundante empleo de los cultismos léxicos, algunos de reciente difusión, como estas dos voces, cuyo uso en hablantes de mediana formación podía caer en la falsa corrección proparoxitónica.

En cuanto a váguido y derivados, se aprecia la necesidad académica de revisar su propuesta etimológica, en cuanto que si de esta forma derivó váido y de aquí vaído, con la innecesaria intercalación de $h$, esta palabra no procede del llano vaguido, porque, de haber existido realmente, habría sido por la vulgar epéntesis consonántica en el anterior hiato, algo que a mi parecer debe descartarse (v. n. 9). Porque no hay compartimentos estancos en la lengua y desde cualquiera de sus variedades se puede extraer datos que aprovechan a su historia, así del lenguaje poético de este cultivado hebreo sobre los esdrújulos ultracorrectos, como también aleccionador es el uso que el rabino Daniel Israel hizo de fee, no porque mantuviera semejante arcaísmo en su habla, sino porque maneja con total perfección una forma que era pura grafía, como cliché de refinamiento en su lengua escrita. Del mismo modo se advierten en su obra las grandes diferencias culturales y lingüísticas que entre los sefarditas se daban, pues mientras este autor con tan delicada perfección juega con el artificioso fee, otros judíos de la diáspora conservaban un tradicional fey perdido en Sefarad. 


\section{REFERENCIAS BIBLIOGRÁFICAS}

Alonso, Amado. 1930. Problemas de dialectología hispanoamericana, IX. Apéndices al tomo I. Biblioteca de Dialectología Hispanoamericana I: 317-370.

Cabezas Alguacil, Concepción. 1988-1989. Un acercamiento a la obra de Daniel López Laguna: Espejo fiel de vidas. Miscelánea de estudios árabes y hebraicos. Sección de hebreo, 37-38, 151-162.

Caro Baroja, Julio. 1978. Los judios de la España moderna y contemporánea. Madrid: Ediciones Istmo, $2^{\mathrm{a}}$ ed., 3 vols.

Carrera de la Red, Micaela. 2008. El vocalismo del español colombiano colonial: estado de la cuestión y propuesta de análisis. En Antonio Álvarez Tejedor et al. (eds.). Lengua viva. Estudios ofrecidos a César Hernández Alonso, pp. 731-745. Valladolid: Universidad de Valladolid.

CORDE: https://www.rae.es/recursos/banco-de-datos/corde (cita: 2020/01/11).

Corominas, JoAn. 1980-1991. Diccionario crítico etimológico castellano e hispánico, con la colaboración de José A. Pascual. Madrid: Editorial Gredos.

Falcón Pérez, María Isabel. 1991. Comercio y comerciantes en Huesca a principios del siglo XV. Aragón en la Edad Media IX, pp. 243-268.

Frago, Juan Antonio. 1996. Goya en su autorretrato lingüístico. Zaragoza: Real Academia de Nobles y Bellas Artes de San Luis.

2012. Lecciones lingüísticas en versos mexicanos de la Independencia. Boletín de la Real Academia Española XCII/CCCV: 59-84.

2017. Primicias sobre variación normativa y diatópica desde el México colonial (1734). Boletín de la Real Academia Española XCVII/CCCXV: 241-256.

2019. Judíos, conversos y judeoespañol. Apuntes históricos. Boletín de Filología 54/1: 153-198.

García de Diego, Vicente. 1985. Diccionario etimológico español e hispánico. Madrid: Espasa Calpe, $2^{\mathrm{a}}$ ed.

KaYserling, M. 1900. The Jews in Jamaica and Daniel Israel Lopez Laguna. The Jewish Quaterly Review 12/4: 708-717.

López Laguna, Daniel Israel. 1720. Espejo fiel de vidas que contiene los Psalmos de David en verso. Obra devota, útil y deleytable. Londres (Espejo fiel).

Morales Padrón, Francisco (ed.). 2004. Diario de don Francisco de Saavedra. Sevilla: Universidad de Sevilla y Consejo Superior de Investigaciones Científicas.

Nebrija, Elio Antonio. 1517/1977. Reglas de orthographía en lengua castellana, edición facsímil. Antonio Quilis (ed.). Bogotá: Instituto Caro y Cuervo.

Nehama, Joseph. 1977. Dictionnaire du judéo-espagnol. Madrid: Consejo Superior de Investigaciones Científicas.

Real Academia Española. 1726-1739/1969. Diccionario de Autoridades, edición facsímil. Madrid: Editorial Gredos (Autoridades). Libros, $23^{\mathrm{a}}$ ed. $(D L E)$.

2014. Diccionario de la lengua española. Barcelona: Espasa

Vicioso, Abelardo. 1979. Santo Domingo en las letras coloniales, 1492-1800. Santo Domingo: Universidad Autónoma de Santo Domingo. 